Article

\title{
Exploring the Sustainable Development of Archaized Block Tourist Destination Based on Communicative Image and Perceptive Image
}

\author{
Kuo-Kuang Fan ${ }^{1}$, Ying Zhou ${ }^{1, *(1)}$ and Jun Zhang ${ }^{2}$ \\ 1 Graduate School of Design, National Yunlin University of Science and Technology, 123 University Road, \\ Section 3, Douliou 64002, Taiwan; fankk@gemail.yuntech.edu.tw \\ 2 School of Design and Art, Yancheng Institute of Technology, Hope Avenue Road 1, Yancheng 224001, China; \\ zj@ycit.cn \\ * Correspondence: d10630023@yuntech.edu.tw
}

check for

updates

Citation: Fan, K.-K.; Zhou, Y.; Zhang,

J. Exploring the Sustainable

Development of Archaized Block

Tourist Destination Based on

Communicative Image and

Perceptive Image. Sustainability 2021,

13, 6858. https://doi.org/10.3390/

su13126858

Academic Editors: Raquel Camprubí and Ariadna Gassiot-Melian

Received: 24 May 2021

Accepted: 9 June 2021

Published: 17 June 2021

Publisher's Note: MDPI stays neutral with regard to jurisdictional claims in published maps and institutional affiliations.

Copyright: (c) 2021 by the authors. Licensee MDPI, Basel, Switzerland. This article is an open access article distributed under the terms and conditions of the Creative Commons Attribution (CC BY) license (https:// creativecommons.org/licenses/by/ $4.0 /)$.

\begin{abstract}
Although archaized blocks have good development prospects as tourist destinations that reshape local characteristics in cities, they have been criticized by academic circles, and most of them are underperforming due to poor management. Therefore, facing the marginalization of the existing archaized streets in various cities, it is urgent to recognize their image and value and find out the strategies that can guide their sustainable development. First of all, we changed the traditional perspective of looking at archaized block cultural attractions through the comparison of a literature review and confirmed that the archaized block should connote a sense of community, fluidity, and publicity and highlight the foundation of local culture and field development. Secondly, we selected a case as the main object and compared the correspondence between the communicative and perceptive images of local residents to construct the connection map of the relationship between local residents and the case field. This part consists of two stages: (1) Through the official information and the intervention of Means-End Chain, we confirm the communicative image and perceptive image of this field, including 13 attributes, 12 consequences, and 11 values; and (2) The collected contents of attributes, consequences, and values were merged and converted into 36 variables to form the evaluation basis for the perceptive images of local residents. Finally, we conducted descriptive statistics, factor analysis, correlation analysis, and multiple linear regression through SPSS 20.0, constructed the A-C-V relation link diagram for the relationship between the field of the case with the local residents, and interpreted the content that should be focused on and the logic behind the constructed image of the field. In addition, the analysis has shown that the archaized block's function is not only meant for tourism, but it also acts as a network information center combining local people, local knowledge, and local cultural resources, thus highlighting the diversity and value of the archaized block. This research not only provides suggestions for the marketing and design organizations of the archaized block to improve the image of the destination, but also to help the inheritance of urban culture.
\end{abstract}

Keywords: archaized block; image; local resident; sustainable development

\section{Introduction}

Recently, there were numerous tourism practices through the construction and marketing of new destinations dominated by cities, among which a large number of resources were wasted in the duplication of destinations with the purpose of capital and political performance [1]. Archaized blocks have become the key destinations of cities because they conform to the needs of the spirit and culture of the times. When China implemented the comprehensive construction of modern cities, historical sites were demolished, leading to the formation of cities with similar images. Therefore, the government tried to build 
archaized blocks to reshape local characteristics and become important city tourism resources [2]. However, archaized blocks have always been criticized by the academic circle. Even when these blocks were advertised in various marketing channels, its image still lacked positivity. [3,4]. This is because of the form of the archaized block that exists the phenomenon of following the trend, competition, and imitation among cities [5], which makes the archaized block become a means to stimulate tourism and commerce by emphasizing a sign operation of cultural identity. At present, archaized blocks are blindly regarded as tourism resources, business development, and means of urban reconstruction, while the identity role of archaized blocks, which also shoulders the cultural value, is ignored [6,7]. Decision-makers carry out various image-building designs and strategic behaviors with a single output based on a lack of the profound and complete cognition of archaized block, further aggravating the conflicts between local residents, tourists, local culture, and themselves [8]. This is not conducive to the positive communication of the archaized block as a tourist destination and will also affect its cognition in the minds of consumers, which ultimately affects the development of the field and the inheritance of urban cultural unity and coherence.

Image is an important condition and foundation for a destination to have a competitive advantage. However, before establishing the image, it is more important to make a targeted assessment of the destination to understand the relationship between its communicative image and its perceptive image [9,10]. The theme park [11,12], also one of the urban tourism destinations, has already been studied, but not much attention has been paid to the related studies of the archaized block. In order to establish a positive image of archaized blocks and achieve their sustainable development path, this study suggests that there are three problems to be solved. Firstly, it is necessary to understand the depth of archaized blocks, instead of spending a lot of money on image design, holding activities, and creating simple archaisms. Secondly, it is necessary to understand the main targeted audiences of the image of the archaized block, which will help us to obtain perceptive information closely related to the field. The archaized block is based on the continuous demand of the city's context, which belongs to the local logic, and the consumers it targets should first be local residents rather than external tourists. This is because the local residents, whether past, present, or future, are an integral part of the local cultural knowledge that provides the diversity of the place and stimulates the outsider's imagination $[13,14]$. Finally, it is necessary to establish the relationship between the communicative information of the field and receivers, which will help us to evaluate the direction of the field development and put forward corresponding adjustment strategies. Hereby, through the exploratory study of a case, this study confirms and obtains the logic behind the views and internal demands of local residents as the recipients of the perceptive image of the archaized block on the communicative image of the case field. The research results show that, in the past, the imitation and marketing methods between cities are not suitable for any archaized block. If the perceived needs of major stakeholders are ignored, the destination marketing work will be negatively affected $[15,16]$. This research not only provides suggestions for the marketing and design organizations of the archaized block to improve the image of the destination, but also to promote the inheritance of urban culture.

\section{Literature Review}

\subsection{Redefine the Concept of the Archaized Block}

Most scholars [17-20] define an archaized block as a representation of the traditional style block of the city that integrates leisure, cultural consumption, commercial real estate, and other industries. It can be seen from the statements of the above scholars that their definition of the archaized block is too macroscopic in content, and the definition fails to highlight its function as a unique tourist place [21]. The generation of the archaized block comes from the combination of signs excavated and refined in the cultural knowledge system belonging to the place. Therefore, the main foothold of the archaized block is a cultural space that meets the needs of modern tourism rather than being operated by 
simple commercial thinking. The original meaning of cultural space refers to a physical space, field, and spot with cultural significance [22]. This indicates that "archaized" is the source of the main content and significance carried by this tourism space, while the block only reflects the presentation type of modern space. Therefore, in this study, the concept of the archaized block will be redefined.

The literal meaning of "archaized" as a combined word is to imitate the form of archaism, but it is far more than the form itself if it is separated to understood. As a verb, "Fang (仿)" is a Pictophonetic character with the meaning of human participation [23]. "Fang (方)", as a structure, is the basis of pronunciation of a character, but when "Fang" is used as a noun, it has a reasonable and conventional meaning [24]. Therefore, "Fang (仿)" can be explained as a behavior that people can enact following certain rules and has a paradigm of dependence. "Gu (古)" is an Ideographic character, representing a new character composed of two or more independent Chinese characters [25], "Gu (古)" is composed of "Shi (十)" and "Kou (口)." "Shi (十)" is a measure word, representing Ten households and means multiple people [26]. "Kou (口)" means mouth [27]. Thus, "Gu (古)" is the way of oral transmission by a group. In addition, "ancient" has an extended meaning to ancient things, including all the past Knowledge content such as text, language, art, beliefs, morality, law, architecture, diet, tools, skills, customs, etc. [25]. "Gu (古)" is the paradigm on which "Fang (仿)" is based. In addition to the tangible, it also carries the intangible cultural sign system. Since "Gu (古)" has a social nature and is a communicable object of mutual identification in a group, "Gu (古)" not only refers to itself but also serves as an intermediary identity that connects the past, present, and future. According to the sign-functions pointed out by Eco [28], "Gu (古)" is both static and dynamic. Static refers to the content, meaning, and associations it reflects. The dynamic sign is based on the original system in the current context through new methods to generate new knowledge processes. This reflects that " $\mathrm{Gu}$ (古)" itself is already a carefully processed material. Whether in the current form of images, words, or architectural entities, it has preset a signifier practice guideline. Therefore, the archaized block means that modern people, according to a certain paradigm, display the community, fluidity, and publicity through the cultural knowledge signs of the material and the non-material. At the same time, the archaized block is a place that gives these signs a new community, fluidity, and public vitality, which in turn guarantees the continuation of cultural knowledge. The community points to people, the mobility points to the extension of history, and the publicity points to equality, which reflects that the basis for the existence of the value of the archaized block is not only the presence of local culture but also the participation of local residents. The local residents refer to the urban residents that are different from the residents of the historical block in the scope of existence. However, in the past, residents were not included in the scope of stakeholders in the construction and consideration of the archaized block.

\subsection{Communicative Image and Perceptive Image of Tourist Destination}

Destination image has been defined by many scholars. For example, it is the sum of beliefs, ideas, and impressions that a person has of a destination [29], and it is the combination and generalization of information of the destination that can most attract tourists and stimulate their motivation [30]. Destination image mainly comes from two expressions: one is the representative image that the destination communicates to consumers selectively by integrating and refining its various elements and resources; the other is the subjective image received by consumers through various media or on-the-spot experiences [31]. From the communicator, destinations need to offer a unique set of products and services that consumers find attractive. Gunn [32] has proposed the concept of the attraction complex, which is derived from the advantages constituted by the characteristics of tourism resources themselves, such as landforms, social and cultural resources, important history, traditional elements, local activities, etc. [33-35]. However, by comparing the core words of destination image, Lai et al. [36] showed that more attention should be paid to the overall and spiritual aspects reflected by the destination, rather than understanding psychological phenomena 
through the synthesis of parts provided by the destination. This is because the feeling of a destination is completely driven by stimuli, and destination attributes will be recorded by our visual sense, but the mental image tends to be fixed on the interpretation. It is therefore not vulnerable to external stimuli and also leads to the mental image not being equal to the visual image $[37,38]$. Therefore, some scholars have proposed the relationship between destination choice and self-consistency [15], which is the deep explanatory power behind the subjective image. A mental image can not only be formed through actual events and imagination but can also foresee events that will happen in the future [38,39]. At present, many researchers use the visual image text of the Internet as the tool of image analysis to distinguish the difference between communicative image and perceptive image, such as Stepchenkova [40], Mak [41], Yao [42], etc. According to Copi [43], and others, the images mentioned in these studies all belong to attribute recognition and lack the semantic dimension of psychological needs. However, since the destination they choose has fixed natural features, visual recognition based on attributes has the effect of adjusting the destination image and its development. Different from the natural landscape, the image construction and development of the archaized block are completely based on the single operation of sign representation function carried out by the government or designers which has not been paid attention to in the part of perceptive image (attribute and psychology). Therefore, this part will be supplemented in this study.

\subsection{Sustainable Development of the Tourist Destination}

In a broad sense, sustainable development is a new idea and strategy in which the goal is to protect the long-term sustainable development capacity of the destination and to ensure that the current and future generations can have the same benefits [44]. At present, many studies have shown that local residents have a positive influence on the sustainable development of destinations. For example, Bichler [45] proposed that local residents have a sense of responsibility for the destination and can provide stimuli for the destination design since they are concerned about local conditions and circumstances. Through enabling the participation of local residents by involving a broader community to negotiate a consensus and adjust the development intentions, long-term development is secured. Tosun [46] stated that local residents are an important basis for ensuring what is effective in local practice. Joppe [47] also said that it is best to consult local residents and ask them to provide feedback on the proposal practice. However, in the field of practical implementation, many scholars [48-50] put forward that the local residents are the stakeholders with the lowest participation in tourism governance and are often excluded from the decision-making of destination design [51]. Li [52] believes that this is because the lifetime, experience, emotion, dreams, and memory of ordinary people have never entered the vocational training of planners and designers, they only follow a certain rule and have the motivation to write the stories of a minority of people who have the power to plan the destinations. Zhang [53] believes that the unique selling points are the strategy choice for sustainable development destinations. As a tourist destination, the existence of the archaized block itself is strategic. According to the concept in Section 2.1, it is a tourism resource for the development of local culture and has the ability to show the difference and uniqueness between the local cultures and the cultures of other cities. The important characteristics are its community, fluidity, and publicity that emphasizes the position of local residents as important and special participants. Therefore, if we hope to achieve sustainable development of archaized blocks, the perceptions of local residents, compared with other tourists, can undoubtedly serve as the basis for guiding the development of archaized blocks.

\section{Research Methodology}

\subsection{Case Selection}

Water Street is an archaized block located in Yannan High-tech Zone, Yancheng City, Jiangsu Province (Figure 1). It is close to the Chuanchang River and next to the buildings of the China Sea Salt Museum. Salt culture had an important political, economic, and cultural 
value to Yancheng in ancient times, as it was a city built by salt. Water Street of Yanzhen is a local cultural attraction built on the background of the salt culture in the hopes of shaping the riches of the salt farmer and salt merchants in ancient times. According to historical records, Yancheng was called the "City of Hundred Rivers" because of its many rivers and bridges [54], so this archaized street was called "Water Street". It is positioned as a Class 4A Tourist Destinations in China, which includes Tianshui Square, Piaozhou Opera Garden, Hanmo Pavilion, Yanzhen Old-Street, Cultural Corner, Salt Merchants Hall, and other special scenic spots. According to the data published by Yan Fu Mass Press Group and Yancheng News Network [55,56], Water Street received more than 500,000 tourists during the Spring Festival in 2019, among which 226,000 tourists were received on a single day of the Lantern Festival. In 2021, the "Spring Festival Temple Fair" received more than 200,000 tourists on that particular day. This shows that Water Street has a great potential as a tourist attraction and should be considered as an important resource for the development of urban tourism in Yancheng.

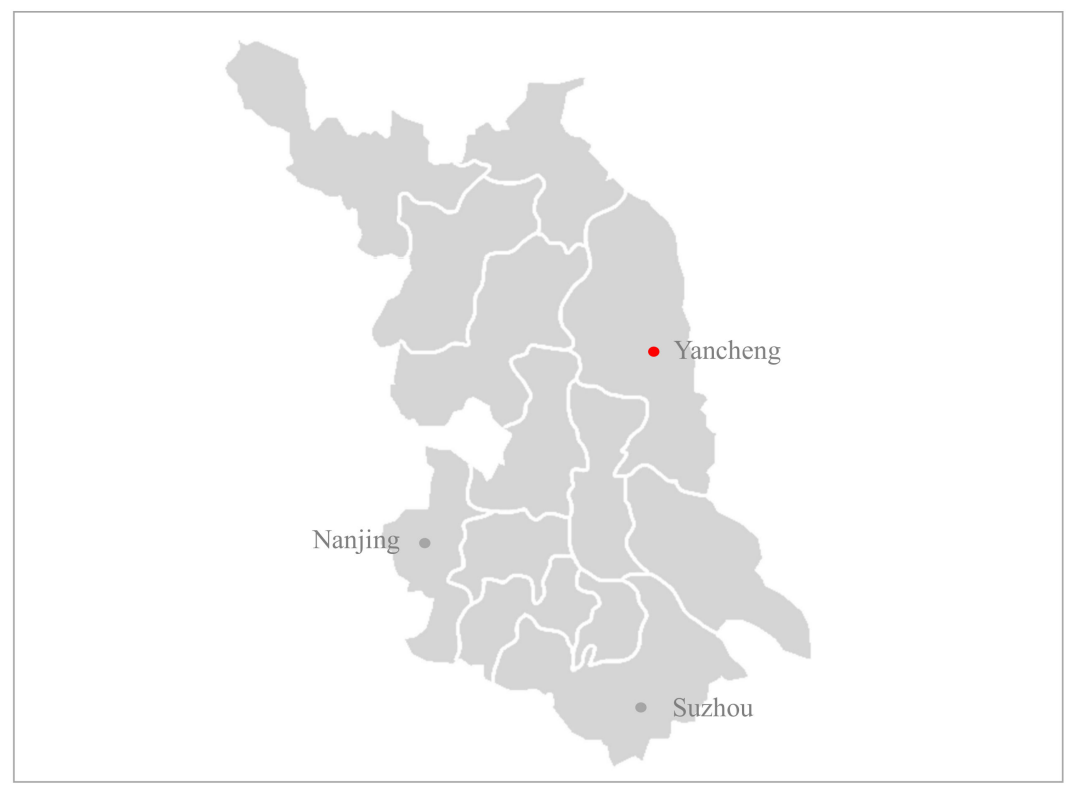

Figure 1. Water Street located in Yancheng, Jiangsu Province, China.

There are three main reasons that this study takes Water Street as the research object. The first reason is that Water Street is located in the researcher's hometown, so the researcher has a profound understanding of its generational and developmental processes. In addition, we can obtain more comprehensive information about this field. Therefore, this case is more suitable than other fields as Rew, Bechtel, and Sapp [57] emphasized that the researcher's self is a tool in the process of data collection and analysis. Secondly, the case study focuses on exploring current events and problems, adopting various methods to collect effective information, which can face the truth and causes that are presented by the object in a detailed manner [58]. Thirdly, this research has positive significance for the Water Street field itself. Yancheng City, where Water Street is located, is not a famous historical and cultural city. The local government hopes to build this space to become an intermediary of the city for external communication. Hence, Water Street plays an important role in local cultural revival and communication, highlighting that this archaized block should not only exist as a tourist attraction. However, since the completion of the project in October 2008, the development of Water Street has not been satisfactory. Except for theme planning activities for holidays, it is almost called an "empty city" by tourists on weekdays, as shown in Figures 2 and 3. At present, some researchers have put forward corresponding development strategies for the problem of Water Street. For example, Qian [59] took the tourism souvenir design of the field as the starting point, Han [60] advocated building the Haiyan brand, etc., but these all belong to the back ends of tourism marketing 
activity. Before developing the backend strategy, we must have a clear cognition about the field's functions, that is to say, the positioning of the front segment is the foundation of the backend design practice. According to the literature in this study, the base point of the archaized block is a local logic in which the authenticity, and fluidity are from the common presence with participation of local residents and local culture. They are the core of the field to maintain diversity, followed by tourists outside the cultural circle. Therefore, this study will include local residents' perception of the field expression as an exploratory attempt to put forward the sustainable development strategy of "Water Street".

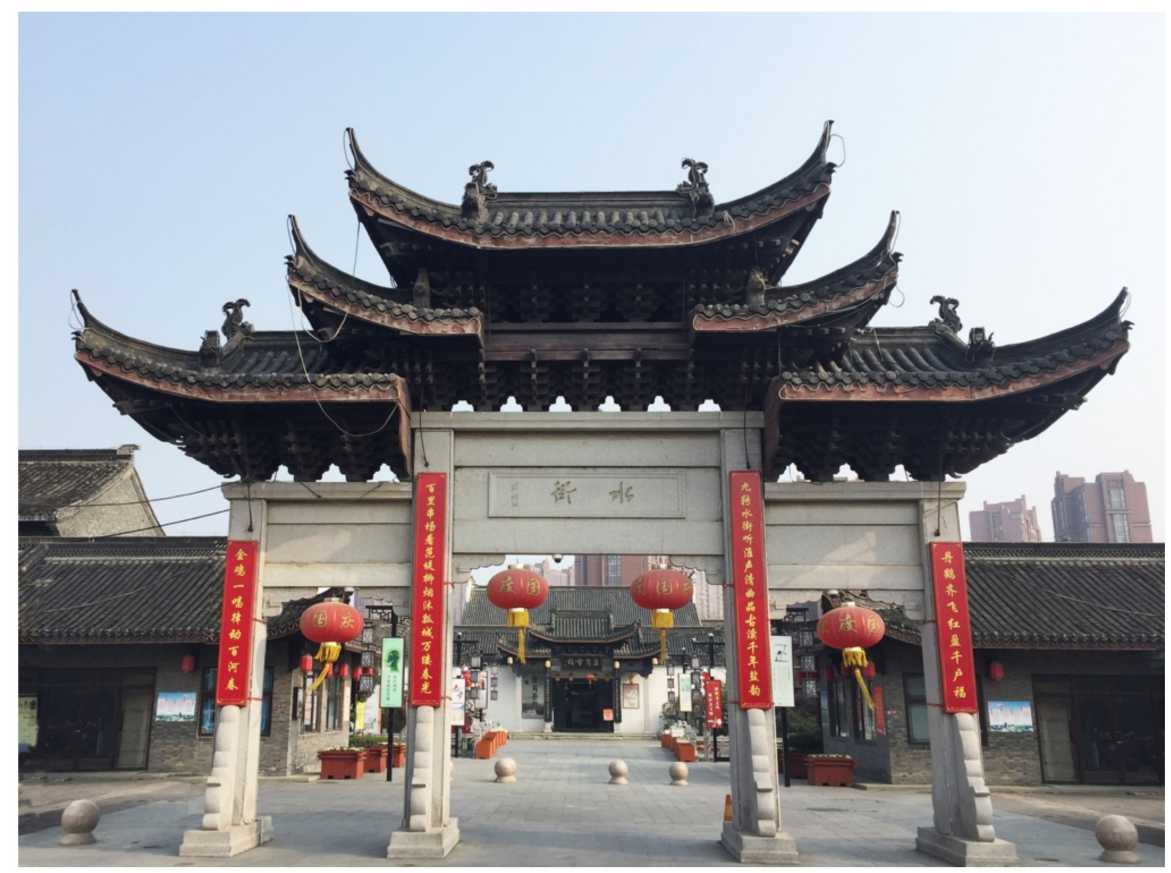

Figure 2. The state of the Water street on weekdays.

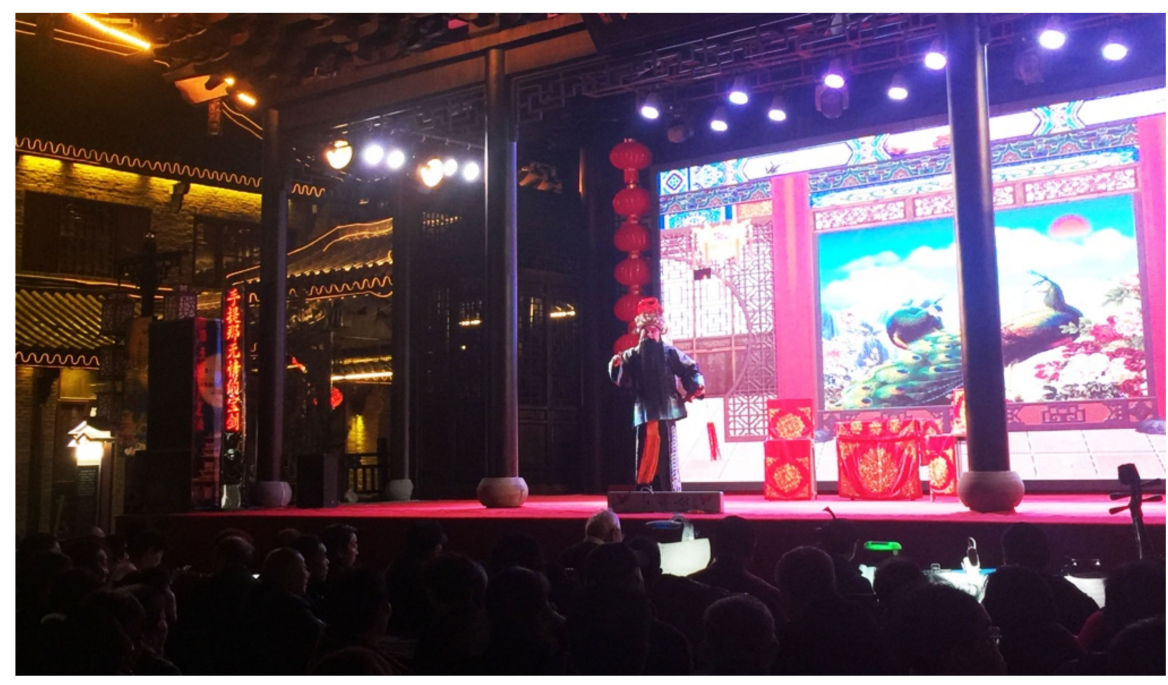

Figure 3. The state of the Water Street during holidays.

\subsection{Data Collection}

\subsubsection{Data Collection Method}

To obtain the communicative and perceptive image of Water Street, in addition to the literature collection of secondary data, this study also adopts the method of the Means-End Chain, hereinafter referred to as "MEC". Here, it is necessary to explain the reasons for the MEC's involvement. The MEC is a method to seek the relationship between the object 
and the subject, which is in line with this study's attempt to explain and evaluate the needs of the target object through the perception of local residents [61]. The main feature of MEC is that people's understanding of information is represented by three widely defined terms, namely, attributes, consequences, and value. The "means" are the materialized objects, while the consequences are derived from the attributes of the materialized object. The "ends" are the final state of a consumer's specific behavior [62]. The attributes (A), consequences (C), and values (V) form an action. Unit-AU is defined as a sequence of planned actions to achieve a goal [63]. In this study, the relationship between the three terms $(\mathrm{A}-\mathrm{C}-\mathrm{V})$ will be used as the basis for data collection and classification.

\subsubsection{Process and Content of Data Collection}

We mainly complete the data collection through three parts.

$\mathrm{C}$ (communicative image of the field form official texts)-The first part is the collection of various official texts about Water Street in Yancheng, including four parts: videos (v), websites (w), commentary (c), and planning (s), mainly from official account platforms and oral information provided by the department responsible for the operation of Water Street. The purpose is to help us fully understand the single communicative image (attributes, consequences, and values) of the field outputs to the public.

$\mathrm{P}$ (perceptive image of the field from expert interview)-The second part is the expert interview which aims to complement the perceptive image (attributes, consequences, and values) that the text in this field should have. According to the interview method of the MEC, the specific interview questions are: What attributes do you think Water Street should have (to guide interviewees to think about the special attributes of archaized blocks)? Why do these attributes attract you and what consequences do they bring to you (to lead the interviewees to think in the consequences hierarchy)? Why is this consequence so important to you (to guide the interviewees to think about the relationship between the personal value with the existence of archaized blocks)? This method can help the interviewees to describe the abstract relationship between these attributes and the psychological level. It is appropriate to use expert interviews as part of the data because experts are not apprehensive about power and capital and are more sensitive to signs and abstract thinking than ordinary people. They have been engaged in research and design related to the development of Water Street and the inheritance of salt culture for a long time, so they are guiding and corrective, ensuring the validity of the follow-up questionnaire content [64]. We interviewed 11 experts in this study, roughly divided into four types: Haiyan cultural researchers, local cultural artists, cultural designers, and local cultural and historical experts. In the actual interview process, there was no restriction on the number of interviewees. It was found that there were multiple repetitions in the content when the interview reached the eleventh respondents, which represents information saturation. Therefore, the number of interviewees ended up being 11 (Table 1). To obtain more in-depth research data, the interview may go back and forth many times, and the time for each respondent may last about 60 to $75 \mathrm{~min}$. (We adopted the interview period: September 2019-October 2020; due to the epidemic situation, the interviews were conducted both via offline and online channels).

$\mathrm{C}+\mathrm{P}$ - The third part is to construct and send the questionnaire content: We analyze the content of the interview scripts about the communicative image $(\mathrm{C})$ and perceptive image (P) obtained from Part I and Part II, respectively. Then, according to the attributes, and the consequences, the value of three-dimensional, refined keyword and the record the frequency of the keywords mentioned were determined, as shown in Table 2, so as to further name the $\mathrm{A}-\mathrm{C}-\mathrm{V}$ items (A1-A13, $\mathrm{C} 1-\mathrm{C} 12, \mathrm{~V} 1-11)$. Content analysis should avoid the influence of the subjective choice of individual researchers. We should invite three people familiar with coding to conduct coding activities simultaneously, as shown in Table 3. Based on the screening results of three people, the intercoder-reliability index of the researchers should be used for reliability analysis $[65,66]$, and take the coefficient greater than 0.6 as the credibility value, as shown in Tables 4 and 5. After ensuring the reliability, the hierarchical 
contents of the two parts were merged and converted into questions of the questionnaire. Then, by using social networks to develop samples between 1 and 28 February 2021, 524 questionnaires were collected from Yancheng residents, and we deleted 78 invalid questionnaires. Then, 446 valid questionnaires were statistically analyzed.

Table 1. Interviewee information list.

\begin{tabular}{cccl}
\hline Interview Date & Code & Gender & Description of the Job \\
\hline 20 September 2019 & HRA & Female & Instructor-Haiyan Folk Culture \\
\hline 2 March 2020 & HRB & Male & Professor-Protection and Development of Haiyan Culture \\
\hline 9 January 2020 & HRT & Female & Instructor-Comparison of Haiyan Culture in Various Regions \\
\hline $\begin{array}{c}\text { 20 January 2020 } \\
\text { 6 May 2020 }\end{array}$ & LR & Male & Professor-Yancheng culture and historical evolution \\
\hline 18 April 2020 & CAA & Female & Performing artist-Huai Opera Performance and Research on Huai Opera \\
\hline 19 April 2020 & CAB & Female & Painting artist-Mainly create with local themes \\
\hline 6 May 2020 & LCA & Male & Design Director-Yancheng related shooting and production of promotional videos \\
\hline 10 May 2020 & LCB & Male & Design Director-Responsible for the design of related cultural products in Yancheng \\
\hline $\begin{array}{c}\text { 2 July 2020 } \\
\text { August 2020 }\end{array}$ & CRA & Male & Professor-Revival and transmission of local culture \\
\hline 27 September 2020 & SDA & Male & Brand Director-Brand promotion and commodity planning \\
\hline 12 October 2020 & SDB & Female & Independent Designer-Creative design of local cultural products \\
\hline
\end{tabular}

Table 2. A-C $-\mathrm{V}$ classification after common open coding $(\mathrm{C}+\mathrm{P})$.

\section{No.}

A1 Traditional art performances

A2 Cultural venues

A3 Architectural information

A4 Traditional festivals

A5 Local souvenirs

A6 Local specialty dining

A7 Trendy dining
Key Description

Source (F)

Traditional handicrafts; Listening to Huai Opera; Cormorant fishing; The office inspects the street; Dragon and Lion Dance; Acrobatics; Face-changing; Shadow play; Peking opera; Traditional stilts; Local skills; Folklore performances; Need to have a local boundary; Cultural axis

Folk Art Collection Center; Wine Culture Museum; Calligraphy and Painting Academy; Calligraphers Association; Antique Market; Make friends in the gazebo with friends who love drama

Antique buildings; Historical performance; Sculptures; Salt Culture Ancestral Hall; Salt Chamber of Commerce; Eight Diagrams Salt Fields; The Office of Yanguan; Yongxing Temple; Bridges; No highlighting of salt culture content; Experience the life of ancient people in the market; Deepen cultural understanding; Historical features; Local characteristics

Lantern Festival; Spring Festival; New Year's Eve praying; Laba share Congee Activities; National Day; The lantern show of the Mid-Autumn Festival; Lack of display of local folklore about the festival

Handicrafts; Agricultural products; Cultural products; Cultural commodities; One of the material forms of local culture; Commemorative items; Characteristic small items; Lack of cultural intermediaries

Eight kinds of special dishes in Yancheng; Special catering; Local snacks; Representative food culture;

McDonald's; Bars; Local snacks; Brands popular with young people; Internet celebrity restaurants; Popular dining 
Table 2. Cont.

$\frac{\text { No. }}{\text { A8 Night scene atmosphere creation }}$

Key Description

Source (F)

National style setting; Lighting renovation; Romantic decoration;

Lack of visibility in the atmosphere; Too much emphasis on lighting; Light show; Colorful lights

The public are in conformity with the crowd and tend to be popular

Well-known scenic spots in Yancheng; A window into salt culture

A10 Public facilities

A11 Suitable for all age groups

A12 Business performance activities

A13 Leisure activities

C1 Can increase the cultural atmosphere of the city

Parking lot; Rest space; Imperfect facilities; Protection

$\mathrm{P}(8)$

Children and the elderly can go; Huai Opera is especially very popular with the elderly; It can be used for the whole family to relax.

Street Dance; Miss Tourism Competition; Circus; Music Festival; 3D Performance

Take a boat; Nostalgic games; Lack of interaction between teaching and entertainment

C (10)

Reveal the local style; Cultural performance; Cultural atmosphere will improve; Local characteristics; local personality; Humanistic atmosphere; Cultural heritage

Cultural circle; Share experience together; Exchange and improve; Learn from each other

C2 Can make people with common interests

Lalt culture; History;

Salt culture; History; City in ancient times; Experience local spirit;

Folk customs; Understand lifestyle; Experience human value; Experience the work of salt

C3 Can understand the historical

knowledge about the local

Reasume hunting; Taking photos in Hanfu; Antique; Fantasy;
Enjoying the sights; Different from other streets; Different

psychological feelings; Retro

\section{C4 Can seek freshness}

Taste special cuisine; Food not available in other places; Satisfy appetite

The memory of the city; The company of time; Miss the good times;

Feel the time; Drive the atmosphere; Cherish the present

The night scene is more beautiful; the field is different; Visually excavating; The scenery;

C5 Can taste local delicacies

C6 Can deepen the emotion between me and the city

C7 Can enjoy the beautiful scenery A place where all the family can work together; Urban emotions;

C8 Can help me get along with my family and friends

C9 Can cultivate the next generation Accompanying friends

Knowledge can be acquired in another way; For children, the field is more intuitive than books

$\mathrm{P}(30)$

$\mathrm{C}(16)$

Tired of the hustle of the city; Feel tired of life; Return to calm;

Relieve tiredness; You can temporarily put down work; You can think; Take a walk

Welfare of surrounding living circle; Convenience; Low cost

Take pictures; Different architectural atmosphere

$\mathrm{P}(14)$

$\mathrm{C}(27)$

$\mathrm{P}(13)$

C (32)

Culture and people's sense of security and acquisition; The pride of the place; The establishment of cultural boundaries

$\mathrm{P}(8)$

$\mathrm{C}(4)$

$\mathrm{P}(16)$

Raise horizons; Increase knowledge; Enrich the mind; Extend

knowledge; Satisfy curiosity; Accumulate experience; Improve cognition experience

Communicate with different people; Get to know more friends;

Increase communication skills; Conducive to weaken unfamiliar boundaries between people; Cohesion cultivation of interpersonal relationships

V4 Improve one's own literacy
Increase cultural atmosphere; Expand cognition ability; Personal progress; Have connotation; Stimulate thinking
$P(10)$

C (23)

$\mathrm{C}(7)$ 
Table 2. Cont.

\begin{tabular}{llll}
\hline \multicolumn{1}{c}{ No. } & \multicolumn{1}{c}{ Key Description } & Source (F) \\
\hline V5 Enjoy the quality of life & Prosperous life; Sentiment & P (4) \\
\hline V6 Get better at work & $\begin{array}{l}\text { Work more efficiently; Work better; Have more motivation for work } \\
\text { and study }\end{array}$ & P (18) \\
\hline V7 Feel the happiness of modern life & $\begin{array}{l}\text { Need to find the feeling of home; Simple and warm; Precious gift; } \\
\text { Better life; Improved life }\end{array}$ & $\begin{array}{l}\text { Obtain respect; A beautiful self; Pride; Vanity is satisfied; } \\
\text { Pelf-confidence; Oneself is different from others; Psychological } \\
\text { satisfaction; Culture can bring self-esteem power }\end{array}$ \\
\hline V8 Gain the respect of others & $\begin{array}{l}\text { Satisfying freshness; Feel calm; Comfortable; Not feeling lonely; } \\
\text { Pleasing to the eye }\end{array}$ & P (19) \\
\hline V9 Feel happy inside & $\begin{array}{l}\text { Love hometown; Inherit local culture; Try to establish cultural } \\
\text { awareness }\end{array}$ & P (21) \\
\hline $\begin{array}{l}\text { V10 Generate a sense of responsibility to } \\
\text { protect local culture }\end{array}$ & $\begin{array}{l}\text { Visual consumption; Psychological consumption; New forms of } \\
\text { consumption; Innovative economy; The evening economic } \\
\text { development }\end{array}$ \\
\hline $\begin{array}{l}\text { V11 A sense of integration with new } \\
\text { consumption patterns }\end{array}$ & & P (3) \\
\hline
\end{tabular}

Table 3. Coder background.

\begin{tabular}{clcc}
\hline Cod3 & & Profession & Background \\
\hline R1 & National Yunlin University of science and technology_Doctoral student & Design \\
\hline R2 & National Yunlin University of science and technology_Doctoral student & Design \\
\hline R3 & National Yunlin University of science and technology-Doctoral student & Design \\
\hline
\end{tabular}

Table 4. Part One common reliability (C).

\begin{tabular}{cccc}
\hline $\begin{array}{c}\text { First } \\
\text { Common Reliability }\end{array}$ & $\begin{array}{c}\text { Second } \\
\text { Common Reliability }\end{array}$ & $\begin{array}{c}\text { Third } \\
\text { Common Reliability }\end{array}$ & $\begin{array}{c}\text { Fourth } \\
\text { Common Reliability }\end{array}$ \\
\hline 0.328 & 0.417 & 0.625 & 0.741 \\
\hline
\end{tabular}

Table 5. Part Two common reliability (Interview-P).

First Common Reliability 0.475
Second Common Reliability

0.605
Third Common Reliability

0.702

\subsection{Research Hypothesis}

According to the MEC, consumers' perceptions of products or services are divided into three types: (1) perception of product attributes; (2) consequences of the perception obtained from product attributes; (3) and the product attributes that help consumers to achieve the perception of personal value [67]. Therefore, based on the research purpose and research method, the following research hypotheses are proposed:

Hypothesis 1 (H1). Local residents' cognition of the attributes of Water Street has a significant impact on the experience consequences they expect to gain from it.

Hypothesis 2 (H2). The experience consequences that local residents expect to gain from the archaized block have a significant impact on their personal values. 
Hypothesis 3 (H3). Local residents' cognition of the attributes of Water Street has a significant impact on their personal value.

\section{Results}

\subsection{Basic Analysis of Samples}

The basic information of the respondents can be seen from Table 6. In terms of gender, males accounts for $48.4 \%$ and females for $51.6 \%$. In terms of age, the proportion of people aged 29-39 was the highest, followed by those aged 18-28 (36.5\%), 40-50 (11.0\%), 51-61 (3.6\%), and over $61(1.3 \%)$. In terms of educational background, the proportion of bachelor's degrees $(68.8 \%)$ and master's degrees or above $(16.6 \%)$ was the highest, while the proportions of other education levels were relatively low. In terms of occupation, the proportion of employees in enterprises (34.5\%) and teachers and public institutions $(25.6 \%)$ was the highest. Every year, $87.4 \%$ of the people go to Water Street one to six times, and another $9.2 \%$ go to Water Street more than six times. Generally speaking, almost all respondents have experience related to the local of Water Street.

Table 6. Basic information form of respondents.

\begin{tabular}{cccc}
\hline Categories & Items & Frequencies & Percentage \\
\hline \multirow{2}{*}{ Gender } & Male & 216 & 48.4 \\
& Female & 230 & 51.6 \\
\hline \multirow{2}{*}{ Age } & $18-28$ years old & 163 & 36.5 \\
& $29-39$ years old & 212 & 37.5 \\
& $40-50$ years old & 49 & 11 \\
& $51-61$ years old & 16 & 3.6 \\
& Over 61 years old & 6 & 1.3 \\
\hline \multirow{2}{*}{ Education } & Below high school & 26 & 5.8 \\
& Post-secondary & 39 & 8.7 \\
& Undergraduate & 307 & 68.8 \\
& Master's degree and above & 74 & 16.6 \\
\hline \multirow{2}{*}{ Occupation } & Student & 101 & 26.6 \\
& Teacher and public-sector & 114 & 25.6 \\
& organization & 43 & 9.6 \\
& Civil servant & 154 & 34.5 \\
& Corporation & 34 & 7.6 \\
\hline
\end{tabular}

\subsection{Reliability and Validity Test of Samples}

\subsubsection{Reliability Test}

As can be seen from Table 7 , the internal consistency coefficient $\alpha>0.7$ of the three levels indicates that the reliability of the three scales is good.

Table 7. Reliability Statistics.

\begin{tabular}{ccc}
\hline & Cronbach's Alpha & N of Items \\
\hline A-layer & 0.701 & 13 \\
\hline C-layer & 0.788 & 12 \\
\hline V-layer & 0.854 & 11 \\
\hline
\end{tabular}

\subsubsection{Validity Test}

As can be seen from Table 8, the KMO of the three scales are all greater than 0.7 [68], and Bartlett's sphericity test shows a significant level, indicating that they are all suitable for factor analysis and that the data have good validity. 
Table 8. KMO and Bartlett's test.

\begin{tabular}{ccccc}
\hline & \multirow{2}{*}{ KMO } & \multicolumn{3}{c}{ Bartlett's Test of Sphericity } \\
\cline { 3 - 5 } & & Approx. Chi-Square & df & Sig. \\
\hline A-layer & 0.721 & 757.244 & 78 & 0.000 \\
\hline C-layer & 0.853 & 984.113 & 66 & 0.000 \\
\hline V-layer & 0.876 & 1529.888 & 55 & 0.000 \\
\hline
\end{tabular}

\subsection{Factor Analysis}

\subsubsection{The A-Layer Factor Analysis}

Principal component analysis was carried out on 13 items in the A-layer using the principal component extraction method. After rotating the axis using the Varimax method, we removed the components with eigenvalues less than one, and a total of four major components were extracted, with the cumulative interpretation variation of $52.806 \%$. As the original item "Suitable for all age groups" has the situation of low load, it was removed. See Tables 9 and 10 for the total variation and the rotated component matrix. The significance of the four main factors are as follows:

Factor 1: Includes four items: "Traditional festivals", "Local specialty dining", "Local souvenirs", and "Traditional art performances". The factor loading is between $0.466 \sim 0.833$. Since most of these items are related to the excavation of local culture and folk customs, they are named "Cultural excavation".

Factor 2: Includes three items: "Business performance activities", "Trendy dining", and "Leisure activities". The factor loading is between 0.653 0.796. Since most of these items are related to modern entertainment and commercial performance to attract popularity, they are named "Modern ways of attracting".

Factor 3: Includes three items: "Public facilities", "Reputation", and "Night scene atmosphere creation". The factor loading is between $0.461 \sim 0.813$. Since most of these items are related to the Water Street decorations and publicity, they are named "Block packaging".

Factor 4: Includes two items: "Cultural venues" and" Architectural information". The factor loading is between 0.695 0.707. Since most of these items are related to the water street related to creating the Water Street cultural atmosphere, they are named "Cultural atmosphere".

Table 9. The A-layer total variance explained.

\begin{tabular}{|c|c|c|c|c|c|c|c|c|c|}
\hline \multicolumn{2}{|c|}{ Component } & \multicolumn{2}{|c|}{ Initial Eigenvalues } & \multicolumn{3}{|c|}{$\begin{array}{l}\text { Extraction Sums of } \\
\text { Squared Loadings }\end{array}$} & \multicolumn{3}{|c|}{$\begin{array}{l}\text { Rotation Sums of } \\
\text { Squared Loadings }\end{array}$} \\
\hline & Total & $\%$ of Variance & Cumulative \% & Total & $\%$ of Variance & Cumulative \% & Total & $\%$ of Variance & Cumulative \% \\
\hline 1 & 2.733 & 22.774 & 22.774 & 2.733 & 22.774 & 22.774 & 1.898 & 15.821 & 15.821 \\
\hline 2 & 1.418 & 11.818 & 34.591 & 1.418 & 11.818 & 34.591 & 1.785 & 14.875 & 30.969 \\
\hline 3 & 1.171 & 9.757 & 44.348 & 1.171 & 9.757 & 44.348 & 1.388 & 11.569 & 42.265 \\
\hline 4 & 1.015 & 8.458 & 52.806 & 1.015 & 8.458 & 52.806 & 1.265 & 10.541 & 52.806 \\
\hline 5 & 0.915 & 7.626 & 60.432 & & & & & & \\
\hline 6 & 0.900 & 7.502 & 67.933 & & & & & & \\
\hline 7 & 0.840 & 6.999 & 74.933 & & & & & & \\
\hline 8 & 0.752 & 6.271 & 81.205 & & & & & & \\
\hline 9 & 0.713 & 5.945 & 87.148 & & & & & & \\
\hline 10 & 0.646 & 5.381 & 92.528 & & & & & & \\
\hline 11 & 0.521 & 4.339 & 96.867 & & & & & & \\
\hline 12 & 0.376 & 3.133 & 100.000 & & & & & & \\
\hline
\end{tabular}


Table 10. The A-layer rotated component matrix ${ }^{\mathrm{a}}$.

\begin{tabular}{|c|c|c|c|c|}
\hline A-Layer & Cultural Excavation & $\begin{array}{l}\text { Modern Ways of } \\
\text { Attracting }\end{array}$ & Block Packaging & Cultural Atmosphere \\
\hline Traditional festivals & 0.833 & & & \\
\hline Local specialty dining & 0.72 & & & \\
\hline Local souvenirs & 0.616 & & & \\
\hline Traditional art performances & 0.466 & & & \\
\hline Business performance activities & & 0.796 & & \\
\hline Trendy dining & & 0.723 & & \\
\hline Leisure activities & & 0.653 & & \\
\hline Public facilities & & & 0.813 & \\
\hline Reputation & & & 0.555 & \\
\hline Night scene atmosphere creation & & & 0.461 & \\
\hline Cultural venues & & & & 0.707 \\
\hline Architectural information & & & & 0.695 \\
\hline
\end{tabular}

Extraction method: Principal component analysis. Rotation method: Varimax with Kaiser normalization. ${ }^{a}$ Rotation converged in five iterations.

\subsubsection{The C-Layer Factor Analysis}

Principal component analysis was carried out on 11 factors in the C-layer by using the principal component extraction method. After rotating the axis by using the Varimax method, the components with eigenvalues less than one were removed, and a total of three major components were extracted, with the cumulative interpretation variation of $52.425 \%$. As the original item "Can enjoy the beautiful scenery" has the situation of low load and cross load, it was removed. See Tables 11 and 12 for the total variation and the rotated component matrix. The significance of the three main factors are as follows:

Factor 1: Includes four items: "Can taste local delicacies", "Can seek freshness", "Can increase the joy of life", and "Make me feel relaxed". The factor loading is between $0.548 \sim 0.750$. Since most of these items are related to self-feelings, they are named "Feeling benefits".

Factor 2: Includes four items: "Can cultivate the next generation", "Save unnecessary leisure expenses", "Can make people with common interests" and "Can help me get along with my family and friends". The factor loading is between $0.491 \sim 0.711$. Since most of these items are related to interpersonal relationships, they are named "Relationship benefits".

Factor 3: Includes three items "Can increase the cultural atmosphere of the city", "Can understand the historical knowledge about the local", and "Can deepen the emotion between me and the city". The factor loading is between $0.609 \sim 0.782$. Since most of these items are related to the relationship between cities, they are named as "City benefits".

Table 11. The C-layer total variance explained.

\begin{tabular}{|c|c|c|c|c|c|c|c|c|c|}
\hline \multirow{2}{*}{ Component } & \multicolumn{3}{|c|}{ Initial Eigenvalues } & \multicolumn{3}{|c|}{$\begin{array}{l}\text { Extraction Sums of } \\
\text { Squared Loadings }\end{array}$} & \multicolumn{3}{|c|}{$\begin{array}{l}\text { Rotation Sums of } \\
\text { Squared Loadings }\end{array}$} \\
\hline & Total & $\begin{array}{c}\% \text { of } \\
\text { Variance }\end{array}$ & $\underset{\%}{\text { Cumulative }}$ & Total & $\begin{array}{c}\% \text { of } \\
\text { Variance }\end{array}$ & $\underset{\%}{\text { Cumulative }}$ & Total & $\begin{array}{c}\% \text { of } \\
\text { Variance }\end{array}$ & Cumulative \% \\
\hline 1 & 3.453 & 31.393 & 31.393 & 3.453 & 31.393 & 31.393 & 2.052 & 18.656 & 18.656 \\
\hline 2 & 1.196 & 10.876 & 42.269 & 1.196 & 10.876 & 42.269 & 1.867 & 16.976 & 35.632 \\
\hline 3 & 1.117 & 10.156 & 52.425 & 1.117 & 10.156 & 52.425 & 1.847 & 16.794 & 52.425 \\
\hline 4 & 0.825 & 7.499 & 59.925 & & & & & & \\
\hline 5 & 0.752 & 6.837 & 66.762 & & & & & & \\
\hline 6 & 0.683 & 6.206 & 72.968 & & & & & & \\
\hline 7 & 0.659 & 5.992 & 78.960 & & & & & & \\
\hline 8 & 0.642 & 5.839 & 84.799 & & & & & & \\
\hline 9 & 0.620 & 5.632 & 90.431 & & & & & & \\
\hline 10 & 0.530 & 4.819 & 95.250 & & & & & & \\
\hline 11 & 0.522 & 4.750 & 100.000 & & & & & & \\
\hline
\end{tabular}


Table 12. The C-layer rotated component matrix ${ }^{\mathrm{a}}$.

\begin{tabular}{|c|c|c|c|}
\hline C-Layer & Feeling Benefits & Relationship Benefits & City Benefits \\
\hline Can taste local delicacies & 0.750 & & \\
\hline Can seek freshness & 0.694 & & \\
\hline Can increase the joy of life & 0.551 & & \\
\hline Make me feel relaxed & 0.548 & & \\
\hline Can cultivate the next generation & & 0.711 & \\
\hline Save unnecessary leisure expenses & & 0.692 & \\
\hline Can make people with common interests & & 0.576 & \\
\hline Can help me get along with my family and friends & & 0.491 & \\
\hline Can increase the cultural atmosphere of the city & & & 0.782 \\
\hline Can understand the historical knowledge about the local & & & 0.665 \\
\hline Can deepen the emotion between me and the city & & & 0.609 \\
\hline
\end{tabular}

Extraction method: Principal component analysis. Rotation method: Varimax with Kaiser normalization. ${ }^{\text {a }}$ Rotation converged in five iterations.

According to the average of the variables in the three factors, the order of importance for local discourse is "City benefits" (6.06), "Feeling benefits" (5.825), and "Relationship benefits" (5.308).

\subsubsection{The V-Layer Factor Analysis}

Principal component analysis was carried out on nine factors in the V-layer by using principal component extraction method. After rotating the axis by using the Varimax method, the components with eigenvalues less than one were removed, and a total of two major components were extracted, with the cumulative interpretation variation of $55.739 \%$. As the original items "Improve one's own literacy" and "Feel happy inside" have low loads and cross loads, they were removed. See Tables 13 and 14 for the total variation and the rotated component matrix. The significance of the two main factors are as follows:

Factor 1: Includes six items: "Get better at work", "Gain the respect of others", "Enjoy the quality of life", " Conducive to the establishment and cultivation of interpersonal relationships", "A sense of integration with new consumption patterns", and "Feel the happiness of modern life". The factor loading is between 0.628 0.785. Since most of these items are related to the value of personal life, they are named "Self-actualization".

Factor 2: Includes three items: "Establish local cultural self-confidence", "Enrich local knowledge and experience", and "Generate a sense of responsibility to protect local culture". The factor loading is between 0.636 0.831. Since most of these items are related to local reputation, they are named "Local-actualization ".

Table 13. The V-layer total variance explained.

\begin{tabular}{|c|c|c|c|c|c|c|c|c|c|}
\hline \multirow{2}{*}{ Component } & \multicolumn{3}{|c|}{ Initial Eigenvalues } & \multicolumn{3}{|c|}{$\begin{array}{l}\text { Extraction Sums of } \\
\text { Squared Loadings }\end{array}$} & \multicolumn{3}{|c|}{$\begin{array}{l}\text { Rotation Sums of } \\
\text { Squared Loadings }\end{array}$} \\
\hline & Total & $\begin{array}{c}\% \text { of } \\
\text { Variance }\end{array}$ & $\underset{\%}{\text { Cumulative }}$ & Total & $\begin{array}{c}\% \text { of } \\
\text { Variance }\end{array}$ & $\underset{\%}{\text { Cumulative }}$ & Total & $\begin{array}{c}\% \text { of } \\
\text { Variance }\end{array}$ & $\underset{\%}{\text { Cumulative }}$ \\
\hline 1 & 3.774 & 41.937 & 41.937 & 3.774 & 41.937 & 41.937 & 3.074 & 34.151 & 34.151 \\
\hline 2 & 1.242 & 13.802 & 55.739 & 1.242 & 13.802 & 55.739 & 1.943 & 21.588 & 55.739 \\
\hline 3 & 0.736 & 8.179 & 63.918 & & & & & & \\
\hline 4 & 0.707 & 7.861 & 71.779 & & & & & & \\
\hline 5 & 0.626 & 6.958 & 78.737 & & & & & & \\
\hline 6 & 0.583 & 6.483 & 85.220 & & & & & & \\
\hline 7 & 0.520 & 5.780 & 91.000 & & & & & & \\
\hline 8 & 0.452 & 5.022 & 96.022 & & & & & & \\
\hline 9 & 0.358 & 3.978 & 100.000 & & & & & & \\
\hline
\end{tabular}

Extraction method: Principal component analysis. 
Table 14. The V-layer rotated component matrix ${ }^{a}$.

\begin{tabular}{lcc}
\hline \multicolumn{1}{c}{ Y-Layer } & Self-Actualization & Local-Actualization \\
\hline Get better at work & 0.785 & 0.770 \\
\hline Gain the respect of others & 0.701 & 0.668 \\
\hline Enjoy the quality of life & 0.642 & 0.831 \\
\hline $\begin{array}{l}\text { Conducive to the establishment and } \\
\text { cultivation of interpersonal relationships }\end{array}$ & 0.628 & 0.799 \\
\hline $\begin{array}{l}\text { A sense of integration with new } \\
\text { consumption patterns }\end{array}$ & & 0.636 \\
\hline $\begin{array}{l}\text { Feel the happiness of modern life } \\
\text { Establish local cultural self-confidence }\end{array}$ & \\
\hline $\begin{array}{l}\text { Enrich local knowledge and experience } \\
\text { Generate a sense of responsibility to } \\
\text { protect local culture }\end{array}$ & \\
\hline $\begin{array}{l}\text { Extraction method: Principal component analysis. Rotation method: Varimax with Kaiser normalization. } \\
\text { Rotation converged in three iterations. }\end{array}$
\end{tabular}

According to the average of the variables in the three factors, the order of importance for local discourse is "Local-actualization" (6.133), "Self-actualization" (5.338).

\subsection{Correlation Analysis}

As shown seen from the factor analysis results in the above section, the A-layer has four main factors: "Cultural excavation", "Modern ways of attracting", "Block packaging", and "Cultural atmosphere". The C-layer has three main factors: "Feeling benefits", "Relational benefits", and "City benefits". The V-layer has two main factors: "Self-actualization" and "Local-actualization". The following correlation matrices contain variables at their respective levels.

It can see from Table 15 that the "Cultural excavation", "Block packaging", and "Cultural atmosphere" of the A-layer are positively correlated with the "Feeling benefits", "Relational benefits", and "City benefits" of the C-layer. The modern ways of attracting in layer A were positively correlated with the "Feeling benefits" and "Relational benefits" of layer C and negatively correlated with "City benefits". The "Feeling benefits", "Relational benefits", and "City benefits" in the C-layer are positively correlated with the "Self-actualization" and "Local-actualization" in layer V. "Cultural excavation", "Block packaging", and "Cultural atmosphere" of the A-layer have positively correlated with the "Self-actualization" and "Local-actualization" in layer V. "Modern ways of attracting" in layer A is only correlated with "Self-actualization".

Table 15. The A, C, and V layer correlation analysis table.

\begin{tabular}{|c|c|c|c|c|c|c|}
\hline & & $\begin{array}{l}\text { Feeling } \\
\text { Benefits }\end{array}$ & $\begin{array}{l}\text { Relationship } \\
\text { Benefits }\end{array}$ & $\begin{array}{c}\text { City } \\
\text { Benefits }\end{array}$ & $\begin{array}{c}\text { Self- } \\
\text { Actualization }\end{array}$ & $\begin{array}{c}\text { Local- } \\
\text { Actualization }\end{array}$ \\
\hline \multirow[b]{2}{*}{ Cultural excavation } & Pearson Correlation & $0.108 *$ & $0.172 * *$ & $0.275 * *$ & $0.207^{* *}$ & $0.218 * *$ \\
\hline & Sig. (2-tailed) & 0.023 & 0.000 & 0.000 & 0.000 & 0.000 \\
\hline \multirow{2}{*}{$\begin{array}{l}\text { Modern ways of } \\
\text { attracting }\end{array}$} & Pearson Correlation & $0.230 * *$ & $0.251 * *$ & $-0.135^{* *}$ & $0.348^{* *}$ & -0.009 \\
\hline & Sig. (2-tailed) & 0.000 & 0.000 & 0.007 & $0.159 * *$ & 0.850 \\
\hline \multirow{2}{*}{ Block packaging } & Pearson Correlation & $0.207 * *$ & $0.124 * *$ & $0.149 * *$ & $0.159 * *$ & $0.183 * *$ \\
\hline & Sig. (2-tailed) & 0.000 & 0.000 & 0.002 & 0.001 & 0.000 \\
\hline Cultural & Pearson Correlation & 0.112 * & $0.242 * *$ & $0.127^{* *}$ & $0.256^{* *}$ & $0.152 * *$ \\
\hline atmosphere & Sig. (2-tailed) & 0.018 & 0.000 & 0.007 & 0.000 & 0.000 \\
\hline \multirow{2}{*}{ Feeling benefits } & Pearson Correlation & & & & $0.377^{* *}$ & $0.241^{* *}$ \\
\hline & Sig. (2-tailed) & & & & 0.000 & 0.000 \\
\hline \multirow{2}{*}{$\begin{array}{l}\text { Relationship } \\
\text { benefits }\end{array}$} & Pearson Correlation & & & & $0.528 * *$ & $0.109 * *$ \\
\hline & Sig. (2-tailed) & & & & 0.000 & 0.022 \\
\hline \multirow{2}{*}{ City benefits } & Pearson Correlation & & & & $0.157^{* *}$ & $0.409^{* *}$ \\
\hline & Sig. (2-tailed) & & & & 0.001 & 0.000 \\
\hline
\end{tabular}




\subsection{Multiple Linear Regression Analysis}

The purpose of multiple linear regression analysis is to further explore the influence degree of the A-layer on the C-layer, the C-layer on the V-layer, and the A-layer on the V-layer based on correlation analysis.

It can be seen from Table 16 that the regression relationship between the independent variables in layer $\mathrm{A}$ and layer $\mathrm{C}$ can explain the variation of the dependent variables of $11.2 \%, 15.9 \%$, and $12.4 \%$, respectively, and the $\mathrm{F}$ test scores of $15.007,21.987$, and 16.747 , respectively. In addition, their $\mathrm{P}$ values are all less than 0.05 . This indicates that at least one of the terms in the regression model is statistically significant. Further analysis revealed that in the regression fitting models of "Cultural excavation", "Modern ways of attracting", "Block packaging", and "Cultural atmosphere", the items of "Feeling benefits", "Relational benefits", and "City benefits" can all be introduced into the equation.

Table 16. The regression equation coefficient test of the A, C, and V layer.

\begin{tabular}{|c|c|c|c|c|c|c|}
\hline & & $\begin{array}{l}\text { Feeling } \\
\text { Benefits }\end{array}$ & $\begin{array}{l}\text { Relationship } \\
\text { Benefits }\end{array}$ & $\begin{array}{c}\text { City } \\
\text { Benefits }\end{array}$ & $\begin{array}{c}\text { Self- } \\
\text { Actualization }\end{array}$ & $\begin{array}{c}\text { Local- } \\
\text { Actualization }\end{array}$ \\
\hline \multirow{2}{*}{ Cultural excavation } & Standardized Coefficients & 0.108 & 0.172 & 0.275 & 0.207 & 0.218 \\
\hline & Sig. & 0.017 & 0.000 & 0.000 & 0.000 & 0.000 \\
\hline \multirow{2}{*}{$\begin{array}{l}\text { Modern ways of } \\
\text { attracting }\end{array}$} & Standardized Coefficients & 0.230 & 0.251 & -0.135 & 0.348 & -0.009 \\
\hline & Sig. & 0.000 & 0.000 & 0.003 & 0.000 & 0.842 \\
\hline \multirow{2}{*}{ Block packaging } & Standardized Coefficients & 0.207 & 0.124 & 0.149 & 0.159 & 0.183 \\
\hline & Sig. & 0.000 & 0.005 & 0.001 & 0.000 & 0.000 \\
\hline \multirow{5}{*}{$\begin{array}{c}\text { Cultural } \\
\text { atmosphere }\end{array}$} & Standardized Coefficients & 0.112 & 0.242 & 0.127 & 0.256 & 0.152 \\
\hline & Sig. & 0.012 & 0.000 & 0.005 & 0.000 & 0.000 \\
\hline & Adjusted R Square & 0.112 & 0.159 & 0.124 & 0.247 & 0.096 \\
\hline & F Test & 15.007 & 21.987 & 16.747 & 37.558 & 12.832 \\
\hline & Sig. & 0.000 & 0.000 & 0.000 & 0.000 & 0.000 \\
\hline \multirow{2}{*}{ Feeling benefits } & Standardized Coefficients & & & & 0.377 & 0.241 \\
\hline & Sig. & & & & 0.000 & 0.000 \\
\hline \multirow{2}{*}{$\begin{array}{l}\text { Relationship } \\
\text { benefits }\end{array}$} & Standardized Coefficients & & & & 0.528 & 0.109 \\
\hline & Sig. & & & & 0.000 & 0.009 \\
\hline \multirow{5}{*}{ City benefits } & Standardized Coefficients & & & & 0.157 & 0.409 \\
\hline & Sig. & & & & 0.000 & 0.000 \\
\hline & Adjusted R Square & & & & 0.441 & 0.232 \\
\hline & F Test & & & & 118.223 & 45.862 \\
\hline & Sig. & & & & 0.000 & 0.000 \\
\hline
\end{tabular}

The regression relationship between the independent variables in layer $\mathrm{C}$ and layer $\mathrm{V}$ can explain the variation of the dependent variables $44.1 \%$ and $23.2 \%$, respectively, and the $\mathrm{F}$ test scores are 118.223 and 45.862 , respectively. In addition, their $P$ values are all less than 0.05 . This indicates that at least one of the terms in the regression model is statistically significant. Further analysis revealed that in the regression fitting models of "Feeling benefits", "Relational benefits", and "City benefits", the items of "Self-actualization" and "Local-actualization" can all be introduced into the equation.

The regression relationship between the independent variables in layer $\mathrm{A}$ and layer $\mathrm{V}$ can explain the variation of the dependent variables $24.7 \%$ and $9.6 \%$, respectively, and the $\mathrm{F}$ test scores are 37.558 and 12.832 , respectively. This indicates that at least one of the terms in the regression model is statistically significant. Further analysis shows that the "Cultural excavation", "Block packaging", and "Cultural atmosphere" are those in which the p-values of "Self-actualization" and "Local-actualization" are all less than 0.05 , so the latter two can be introduced into the equation. However, the modern ways of attracting in which the $p$-value of "Local realization" is greater than 0.05 , so it is eliminated and not introduced into the equation.

Through the above multiple linear regression analysis process, it can be seen that in hypothesis H1, "Cultural excavation", "Modern ways of attracting", "Block packaging", and "Cultural atmosphere" of the A-layer have a significant influence on the "Feeling 
benefits", "Relational benefits", and "City benefits" of the C-layer. In hypothesis $\mathrm{H} 2$, the "Feeling benefits", "Relational benefits", and "City benefits" of the C-layer significantly influence the "Self-actualization" and "Local-actualization" of the V-layer. In hypothesis $\mathrm{H} 3$, the "Cultural excavation", "Block packaging", and "Cultural atmosphere" of the Alayer have a significant influence on the "Self-actualization" and "Local-actualization" of the V-layer. The "Modern ways of attracting" of A-layer only had a significant influence on the "self-actualization" of the V-layer.

\section{Discussion}

According to the importance of each factor and the correlation coefficient of factors at different levels in the results, we established the communicative image that should be paid attention to for Water Street based on the perceptive image and logic of local residents. On the attribute layer of Water Street's communicative image, this study divided it into four factors: "Cultural Excavation", "Modern ways of attracting", "Block packaging", and "Cultural atmosphere". Among them, "Cultural Atmosphere" is of the utmost importance. On the consequences layer of Water Street's perceptive image, this study divided it into three factors: "Feeling benefits", "Relational benefits", and "City benefits", among which "City benefits" received more attention. In the layer of the personal value of the perceptive image, this research divides it into two factors: "Self-actualization" and "Local-actualization", among which "Local-actualization" has the highest score. To further distinguish the core relationship of the attribute layer, we conducted screening according to the size of the correlation coefficient and the degree of attention paid to it. Finally, a link diagram for evaluating the development of the water street's communicative image from the perspective of local residents was formed, as shown in Figure 4.

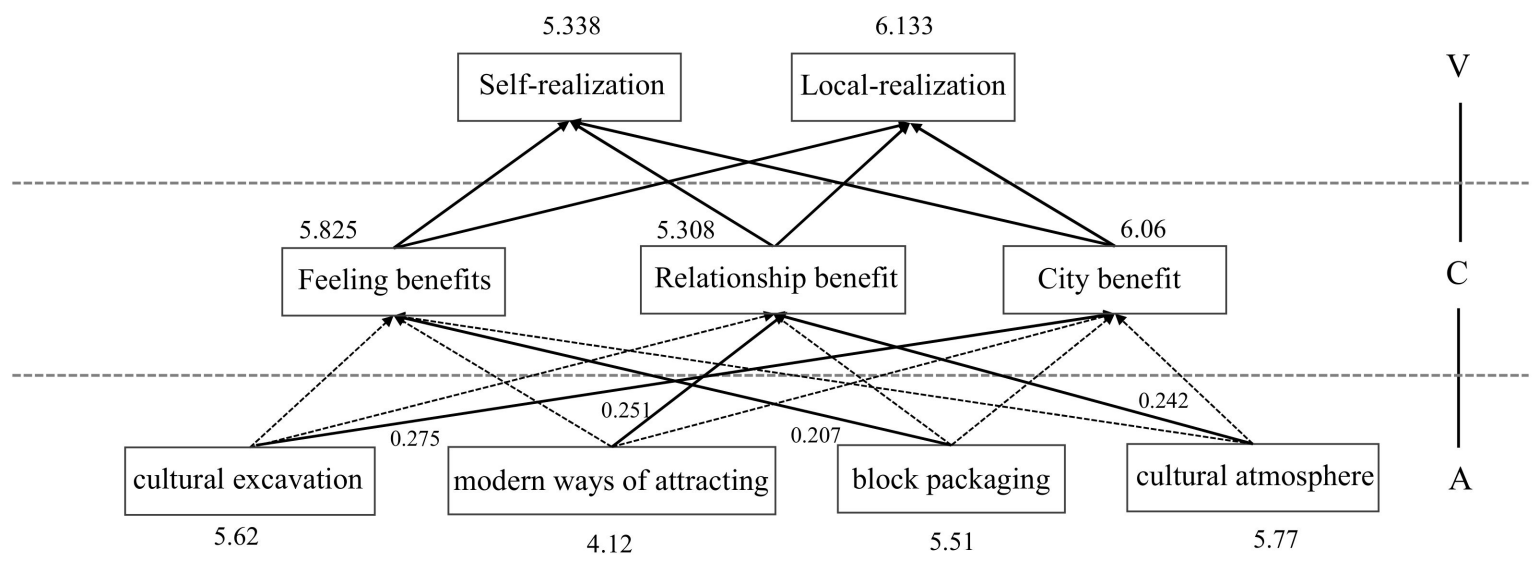

Figure 4. Local residents' evaluation of the development structure of the communicative image of Water Street.

First, there are the "Cultural venues" and "Architectural information", which are related to the "Cultural atmosphere". When viewed from the perspective of "Architectural information", it both refers to the form of archaized buildings and also the content conveyed by these buildings. It can not only link historical authenticity with the modern interpretation, but also help to convey local knowledge. For example, the Water City Gate recorded in Yancheng County Chronicles of Wanli (1987): “The direction of Yancheng's construction is from the northwest to the south, and residents gather in the southeast, so it is impossible to do without the south gate ... Goods in Yancheng are transported through the south gate, making the life of residents convenient" [69]. We can see the importance of the Water City Gate to Water Street, but this is not mentioned in the water street field or the official publicity materials. Therefore, it is necessary to increase the channels through which architectural messages are widely recognized. Viewed from the perspective of "Cultural venues", for example, painting and calligraphy, academies, or opera venues can help the local people in a certain cultural circle form a cultural group to 
expand communication and interpersonal channels and ensure the quality of leisure life for local people. Therefore, Water Street should pay attention to its cultural groups and give corresponding encouragement and support to help publicize the role and power of cultural groups, thereby expanding and creating other cultural groups of the local culture, integrating local people into the local knowledge system, and converting the role of the local people from the viewers to the inheritors.

Secondly, there are "Traditional art performances", "Traditional festivals", "Local souvenirs", and "Local specialty dining", all of which are related to cultural excavation and the transformation of knowledge signs. They can enhance the cultural atmosphere of the city, help local residents understand the historical lifestyle of the city in the past, satisfy the cultural confidence of local residents, and stimulate their demand to participate in the preservation of local traditional culture. Therefore, while paying attention to the field's cultural boundary, that is, taking salt culture as the mainline, we can explore the traditional events and knowledge supplemented by other intangible cultural heritages in Yancheng to express the spirit and character of local culture through performances, experiential activities, cultural products, food culture, and other forms. Although Water Street takes the rich economy of salt merchants as the mainline, the information conveyed by the sculptures of salt people and the history of salt culture in the field is in contradiction with the economic prosperity. This case neglected the local spirit of the salt people with perseverance and hard work, which is the cultural embodiment of local characteristics, so it can be paid attention to with the help of various forms of communication.

Thirdly, there are "Public facilities", "Reputation", and "Night scene atmosphere creation", which are all related to the packaging of the field. "Public facilities" and "Night scene atmosphere creation" involve hardware and software packaging of site entities, while "reputation" involves the creation of site image communication. The first two points help provide local residents with a new experience space where they can get a moment of rest in the rapid urban life and adjust to their state better. Therefore, in addition to providing a visual experience, they can also emphasize relaxation by combining the visual with other senses. The latter's publicity can stimulate the freshness of the new space for local residents to actively connect with the space. Therefore, the publicity channels need to be expanded, such as establishing a special website belonging to the block and the integration of relevant information of the field through new media.

Finally, there are "Trendy dining", "Business performance activities", and "Leisure activities", which are all related to the way the modern commerce atmosphere attracts people. Local residents can certainly explain their logic, such as providing new activities for parents, children, and friends to participate in. However, this part is weaker than other attributes, and it is negatively correlated with "City benefit". Therefore, as local residents pay more attention to "City benefit" and the needs of "Local-actualization", the planners can appropriately weaken this aspect in the field of Water Street.

According to the number of attributes $(\mathrm{C})$ of the single communicative image of Water Street, we find that the least important attributes considered by local residents is the most important attribute in the single communicative image of Water Street. In contrast, the attribute most valued by local residents is only mentioned five times in the communicative image. Therefore, we can see that the attributes that the Water Street communications attach importance to and the orientation of the field based on this communication are different from local residents' demand for the archaized block. Even though Water Street's communicative image has the attributes of the traditional culture, this study demonstrates the local residents and local culture mutually reflect local needs, which are the basis of existence and sustainable development of the archaized block. Therefore, the activities carried out in the water street field are not the focus, but the unique character of the local or city behind the form of these activities. Therefore, the local residents are the most important group for the tourists in Water Street because the cultural demand for the place, from their perspective, is an integral part of the local culture, which is of positive significance to the tourists from outside who want to know the place or the city. Therefore, it is of 
guiding practical value for the current situation of Water Street to adjust the attributes of its communicative image based on this.

\section{Conclusions}

As a tourist destination in the city, archaized blocks have good development prospects as tourist destinations that reshape local characteristics in cities and as its sustainable development meaning is to establish an emotional relationship between contemporary and future residents within the urban culture. Along with the improvement of living quality, modern tourist destinations influenced by the reaction of material and productive space position begin to weaken gradually as more and more people pay attention to spiritual and cultural life experiences, hoping to improve the quality of life, improve our character, and thus shape cultural self-confidence, and eventually form a personal, regional, urban, and even national identity [70]. Therefore, the archaized block meets the needs of the spirit of modern life and have the reality, value, and purpose of their existence. This further emphasizes that the study of archaized block should not only stay in the material property of the field, but also pay attention to the spiritual connection expressed by the field attributes.

Facing the problems mentioned in the introduction, first of all, we reinterpreted the concept of the archaized block. We confirmed that in the development of the archaized block, local residents are equally important influences with local culture on the communicative image of the field. Secondly, by taking Water Street as a case, we constructed an A-C-V link diagram of the relationship between Water Street and its local residents by collecting its communicative image and perceptive image. Then, we adjusted and interpreted the attributes that the block should pay attention to and the logic behind the communicative image of this area. The research results also show that the archaized block's field function is not only a form of the tourism economy, but also a network information center combining local people, local knowledge, and local cultural resources, thus highlighting the diversity and authenticity of the archaized block. In this section, we will discuss the theoretical and practical implications of this research.

\subsection{Theoretical Significance}

First of all, through the related research on the archaized block, it is found that few studies discuss the definition of the archaized block from the concept itself. In this study, therefore, to make a definition of the archaized block that the archaized block means that modern people, according to a certain paradigm, display the community, fluidity, and publicity through the cultural knowledge signs of the material and the non-material. At the same time, the archaized block is a place to give these signs a new community, fluidity, and public vitality, which, in turn, guarantees the continuation of cultural knowledge. In this definition, the community highlights the important foundation of the local residents for the archaized block, the fluidity highlights the cultural inheritance function of the archaized block, and the publicity emphasizes the necessity of bringing the local discourse into the field, rather than dividing it into a few designers' and planners' achievements. Secondly, most studies are about the criticism of the archaized block, but seldom discuss how to develop the archaized block and help them change their current negative image and development status. Therefore, this study evaluates the communicative image of the field by combining the communicative image and the perceptive image of the archaized block. Finally, few studies have focused on the relationship between local residents and the archaized block, but based on the definition of the concept, the presence of local residents and local culture ensure the motivation for the sustainable development of the field. Therefore, this research takes a case as the object, based on the evaluation of local residents on the communicative and perceptive image to construct the link between the archaized block with the local residents' demands, and further puts forward the corresponding improvement strategy of sustainable development. 


\subsection{Practical Significance}

Culture is an advantage for a place to develop tourist destinations and maintain its diversity. The results of this study prove the value of the existence of the archaized block and explore the motivation of sustainable development of the archaized block. This study also provides suggestions for the development of field management, designers, and planners. The government can also use the links with the main stakeholders to help promote the local cultural resources and cooperate with the archaized block to achieve the win-win situation of the city's modern appearance and local spirit.

\subsection{Limitations and Future of Research}

Due to the differences among the blocks, the results of this study are not completely suitable for other archaized blocks. This is because the content of the questionnaire covers the opinions of local experts. In a different field, experts with different knowledge backgrounds may consider other communicative images and perceptive images. However, the inclusion of the local residents' discourse in the development of the decision-making of the archaized block in this study is based on the discussion of its concept. As an exploratory study, the method and thinking of this study are feasible. Local residents are the starting point and the basis. In the future, it is still necessary to discuss the role and influence of tourists outside the cultural circle in the sustainable development of the archaized block.

Author Contributions: Conceptualization: Y.Z.; methodology: K.-K.F., Y.Z.; validation: Y.Z.; formal analysis: Y.Z.; investigation: Y.Z. and J.Z.; resources: Y.Z.; writing-original draft preparation: Y.Z.; writing-review and editing: Y.Z.; supervision: K.-K.F. All authors have read and agreed to the published version of the manuscript.

Funding: This research was funded by the Taiwan Ministry of Science and Technology, grant number 109WFA2610412. This research was supported by the project Program of Philosophy and Social Science Research in Jiangsu Universities (No. 17YSB016), China. This research was supported by the Program of Jiangsu Social Science Foundation Youth Project in 2019 (No. 19YSC005), China.

Informed Consent Statement: Informed consent was obtained from all subjects involved in the study.

Acknowledgments: We would like to express our gratitude to the Taiwan Ministry of Science and Technology for providing research resources for this study. We would like to express our gratitude to the project Program of Philosophy and Social Science Research in Jiangsu Universities for providing research resources for this study.

Conflicts of Interest: The authors declare no conflict of interest.

\section{References}

1. Steven, M. Spaces for Consumption, 1st ed.; SAGE Publications Ltd.: Los Angeles, CA, USA, 2010.

2. Fan., Y.L. The Significance of the Construction of City Image in the Antique Street: Taking JinLi Street and Kuanzhai Alley as an Example. Master's Thesis, Sichuan Agriculture University, Ya'an, China, 2016.

3. Feng, J. Technical path of authentic display of cultural heritage-A case study of Xi'an Great Ruins. J. Chang'an Univ. 2017, 69, 23-30.

4. Tang, T. The Protection of Historical Cities Cannot be Blindly Retro, We Must Merge the Old and the New. Science and Technology Daily. 5 December 2019. Available online: http:/ / digitalpaper.stdaily.com/http_www.kjrb.com/kjrb/html/2019-12/05/content_ 436158.htm?div=0 (accessed on 23 May 2020).

5. Qu, Y.X. Copycat Cultural Relics Emerge Endlessly, How to Avoid to one Face for a Thousand Archaized Block. Workers' Daily. 27 December 2020. Available online: http:/ / www.chinanews.com/sh/2020/12-27/9372134.shtml (accessed on 12 March 2021).

6. Liu, L.; Lei, Y.H. Preliminary study on the design of antique commercial block. Urban Archit. 2013, 12, 10-11.

7. Chen, S.F. Future-oriented business model innovation of cultural industry. J. Beijing Univ. 2019, 17, 38-41.

8. He, J. Nostalgia of the Ancient Town Tourists \& Ancient Town Development. Master's Thesis, Chongqing Normal University, Chongqing, China, 2011.

9. Almeida-Santana, A.; Moreno-Gil, S. Perceived Sustainable Destination Image: Implications for Marketing Strategies in Europe. Sustainability 2019, 11, 6466. [CrossRef]

10. Chen, J.; Wu, G.Q. Progress and Prospect of China's Tourism Image Study. Geogr. Geo-Inf. Sci. 2004, $20,73-77$.

11. Zhang, Y.; Li, X.; Cárdenas, D.A.; Liu, Y. Calculating Theme Parks' Tourism Demand and Attractiveness Energy: A Reverse Gravity Model and Particle Swarm Optimization. J. Travel Res. 2021. [CrossRef] 
12. Chang, W.J.; Chung, Y.C.; Huang, R.Y.; Yin, Y.S. Relationships among travel motivation, destination image and tourist satisfactionA study of Farglory Ocean Park, Hualien. Res. Lewis Ind. 2017, 15, 50-66.

13. Andereck, K.L.; Nyaupane, G.P. Exploring the nature of tourism and quality of life perceptions among residents. J. Travel Res. 2010, 50, 248-260. [CrossRef]

14. Elliot, S.; Papadopoulos, N.; Kim, S.S. An integrative model of place image: Exploring relationships between destination, product, and country images. J. Travel Res. 2011, 50, 520-534. [CrossRef]

15. Šegota, T.; Chen, N.; Golja, T. The Impact of Self-Congruity and Evaluation of the Place on WOM: Perspectives of Tourism Destination Residents. J. Travel Res. 2021. [CrossRef]

16. Yu, Z.; Zhao, X.H.; Li, M. Residents' sense of place in tourist destinations: Theories, methods and research hotspots. J. Beihua Univ. 2020, 21, 79-90.

17. Mao, Z. Research on Tourism Development of Archaized Streets in Chengdu. Master's Thesis, Sichuan University, Chengdu, China, 2007.

18. Shang, Y.Y. The Psychological Root on The Boom of Archaize Commercial Street. J. Hebei Polytech. Univ. Soc. Sci. Ed. 2012, 05, $11-12$.

19. Zou, Y. Analysis of Tourism Experience in Chengdu Archaize Street District. Econ. Travel 2017, 21, $152-153$.

20. Qiu, J.; Liu, Y.Y. On the Future Development of Archaized streets. J. Jilin Jianzhu Univ. 2020, 3, 75-79.

21. Eastern Morning Newspaper. The Director of National Cultural Relics Calls for Stopping Archaized Commercial Street. Yuanlin Net. 21 January 2011. Available online: http:/ / news.yuanlin.com/detail/2011121/76323.htm (accessed on 10 June 2020).

22. Xiang, Y.J. Discuss on the Cultural Spac. J. Minzu Univ. 2008, 35, 81-88.

23. Fang(仿). Baidu Chinese Language. Available online: https://baike.baidu.com/item/\%E4\%BB\%BF/4592111?fr=aladdin (accessed on 6 July 2020).

24. Fang(方). Baidu Chinese Language. Available online: https://hanyu.baidu.com/zici/s?wd=\%E6\%96\%B9\&quer=\%E6\%96\%B9 $\&$ srcid $=28232 \&$ from $=\mathrm{kg} 0$ (accessed on 6 July 2020).

25. $\mathrm{Gu}$ (古). Baidu Chinese language. Available online: https://hanyu.baidu.com/s?wd=\%E5\%8F\%A4\&from=zici (accessed on 8 July 2020).

26. Shi(十). Baidu Chinese Language. Available online: https://hanyu.baidu.com/s?wd=\%E5\%8D\%81\&from=zici (accessed on 8 July 2020).

27. $\operatorname{Kou}(\square)$. Baidu Chinese Language. Available online: https://baike.baidu.com/item/\%E5\%8F\%A3/4676525 (accessed on 8 July 2020).

28. Eco, U. A Theory of Semiotics; Indiana University Press: Bloomington, IN, USA, 1978; ISBN 9780253202178.

29. Crompton, J.L. An assessment of the image of Mexico as a vacation destination and the influence of geographical location upon that image. J. Travel Res. 1979, 17, 18-23. [CrossRef]

30. Li, L.L. Tourism Destination Image Planning: Theory and Practice; Guangdong Travel \& Tourism Press: Guangzhou, China, 2008.

31. Gao, J. Tourism Destination Image, Positioning and Branding: Conceptual Analysis and Relationship Model. Tour. Trib. 2009, 24, 25-30.

32. Gunn, C.; Var, T. Tourism Planning: Basics, Concepts, Cases, 4th ed.; Routledge: London, UK, 2020.

33. Barney, J.B. Firm resources and sustained competitive advantage. J. Manag. 1991, 17, 99-120. [CrossRef]

34. Deng, J.; King, B.; Bauer, T. Evaluating natural attractions for tourism. Ann. Tour. Res. 2002, 29, 422-438. [CrossRef]

35. Laws, E. Tourist Destination Management: Issues; Analysis and Policies; Routledge: London, UK, 1995.

36. Lai, K.; Li, X. Tourism destination image: Conceptual problems and definitional solutions. J. Travel Res. 2016, 55, 1065-1080. [CrossRef]

37. Zimbardo, P.G.; Johnson, R.L.; McCann, V. Psychology: Core Concepts, 6th ed.; Pearson: Boston, MA, USA, 2009.

38. Anderson, J.R. Cognitive Psychology and Its Implications, 7th ed.; Worth Publishers: New York, NY, USA, 2009.

39. Heil, J. Philosophy of Mind: A Contemporary Introduction, 3rd ed.; Routledge: London, UK, 2013.

40. Stepchenkova, S.; Zhan, F. Visual destination images of Peru: Comparative content analysis of DMO and user-generated photography. Tour. Manag. 2013, 36, 590-601. [CrossRef]

41. Mak, A.H. Online destination image: Comparing national tourism organisation's and tourists' perspectives. Tour. Manag. 2017, 60, 280-297. [CrossRef]

42. Yao, X.K. Tourism Destination Image Evaluation from the Perspective of Online Tourism. Master's Thesis, Nanjing University of Posts and Telecommunications, Nanjing, China, 2020.

43. Copi, I.M.; Cohen, C. Introduction to Logic; Upper Saddle River: New York, NY, USA, 2005.

44. Wang, Q.S.; Zhang, Y.Z. Evaluation of Sustainable Development Competitiveness of Cultural Tourism Destination: A Case Study. Areal Res. Dev. 2017, 36, 83-87.

45. Bichler, B.F. Designing tourism governance: The role of local residents. J. Destin. Mark. Manag. 2019, 100389. [CrossRef]

46. Tosun, C. Expected nature of community participation in tourism development. Tour. Manag. 2006, 27, 493-504. [CrossRef]

47. Joppe, M. Tourism policy and governance: Quo vadis? Tour. Manag. Perspect. 2018, 25, 201-204. [CrossRef]

48. Bornhorst, T.; Ritchie, B.J.R.; Brent, J.R.; Sheehan, L. Determinants of tourism success for DMOs \& destinations: An empirical examination of stakeholders' perspectives. Tour. Manag. 2010, 31, 572-589. 
49. Moscardo, G. Exploring social representations of tourism planning: Issues for governance. J. Sustain. Tour. 2011, 19, 423-436. [CrossRef]

50. Peters, M.; Strobl, A. Toward a theory of destination governance. In Contemporary Destination Governance: A Case Study Approach, 1st ed.; Pechlaner, H., Beritelli, P., Pichler, S., Peters, M., Scott, N., Eds.; Emerald Books: Bingley, UK, 2015; pp. $223-232$.

51. Hatipoglu, B.; Alvarez, M.D.; Ertuna, B. Barriers to stakeholder involvement in the planning of sustainable tourism: The case of the Thrace region in Turkey. J. Clean. Prod. 2016, 111, 306-317. [CrossRef]

52. Li, N. Kensington Market: Collective Memory, Public History and Toronto's Urban Landscape; Shanghai Sanlian Bookstore Co., Ltd.: Shanghai, China, 2017.

53. Zhang, C. Competitive Strategy Study of Sustainable Destination. Nankai Bus. Rev. 2002, 5, 69-73.

54. Yu, H.G. On the Status of the Culture of Sea Salt in Rebuilding the Image of Modern Salt City. J. Sichuan Univ. Sci. Eng. 2006, 21, 15-19.

55. Yan Fu Mass Press Group. Water Street Lantern Festival Once Again on the "Xinwen Lianbo". Available online: http://jsnews. jschina.com.cn/yc/a/201902/t20190222_2239379.shtml (accessed on 7 June 2021).

56. Yancheng News. More than 200,000 People Clocked in at the Water Street Temple Fair in Yancheng. Available online: http: / /jsnews.jschina.com.cn/yc/a/202103/t20210301_2737033.shtml (accessed on 7 June 2021).

57. Rew, L.; Bechtel, D.; Sapp, A. Self as an instrument in qualitative research. Nurs. Res. 1993, 16, 300-301. [CrossRef]

58. Guan, X.S.; Ruan, L.Y.; Wang, M.T.; Wang, L.T.; Li, P.L.; Gao, X.F.; Huang, L.C.; Huang, R.S.; Chen, S.C.; Chen, Y.Z.; et al. Design Research Methods, 4th ed.; Quanhua Tech. Inc.: Taipei, Taiwan, 2018.

59. Qian, F. Yancheng Tourism Souvenir Design Study under the Geographical and Cultural Background. Master's Thesis, Soochow University, Soochow, China, 2014.

60. Han, S. Research of Sea Salt Culture and Demonstration of Regional Development-In yancheng city, jiangsu province as an example. Sci. Technol. Inform. 2008, 34, 34-35.

61. Reynolds, T.J.; Olson, J.C. (Eds.) Understanding Consumer Decision Making: The Means-End Approach to Marketing and Advertising Strategy; Psychology Press: London, UK, 2001.

62. Gutman, J. A means-end chain model based on consumer categorization processes. J. Mark. 1982, 46, 60-72. [CrossRef]

63. Gutman, J. Means-end chains as goal hierarchies. Psychol. Mark. 1997, 14, 545-560. [CrossRef]

64. Dorussen, H.; Lenz, H.; Blavoukos, S. Assessing the reliability and validity of expert interviews. Eur. Union Politics 2005, 6, 315-337. [CrossRef]

65. Martin, P.; Bateson, P. Measuring Behaviour: An Introductory Guide, 2nd ed.; Cambridge University Press: New York, NY, USA, 1993.

66. Winter, D.G. Manual for Scoring Motive Imagery in Running Text, 3rd ed.; Unpublished Manuscript; Department of Psychology, University of Michigan: Ann Arbor, MI, USA, 1991.

67. Skytte, H.; Bove, K. The concept of retailer value: A means-end chain analysis. Agribusiness 2004, 20, 323-345. [CrossRef]

68. Kaiser, H.F. An index of factorial simplicity. Psychometrika 1974, 39, 31-36. [CrossRef]

69. Yang, R.Y.; Xia, Y.X. Wanli Yancheng County Annals; Liu, Z.Y., Ed.; Student Book Co., Ltd.: Taipei, Taiwan, 1987.

70. Li, W.T. A study on the Design of Ritual Image of Products. Ph.D. Thesis, National Yunlin University of Science and Technology, Yunlin, Taiwan, 2018. 